\title{
Prediction of scour in overtopped floodwalls using JET and EFA
}

\author{
P. Safarian Bahri, A. Osouli, Ph.D. P.E, E. Stendback \\ Southern Illinois University Edwardsville, IL, USA
}

\begin{abstract}
Erosion due to water overtopping of floodwalls is one of the main causes of levee failures during storms events. Prediction of scour rate and depth in fine grained material has always been a critical issue for engineers. Performing full scale erosion tests on geo-structures like levees can be difficult and expensive. However, JET and EFA test are alternative tests to determine the scour potential of a soil. JET can be conducted both in the lab and in-situ, while EFA is conducted in the laboratory. In this study, a series of laboratory JET, EFA, and lab-scaled levee-floodwall erosion tests have been conducted on material retrieved from Mississippi River bank. The results of erosion rate on these soils have been compared. In addition, a correlation is proposed to estimate the erosion rate that occurs during floodwall overtopping in crest of levees based on JET and EFA results for soils with various compactions and plasticity indices.
\end{abstract}

\section{INTRODUCTION}

Erosion due to floodwall overtopping has been one of the main causes of earthen embankments failures in New Orleans, Hawaii, California, and Midwest floods in 2008 (Villarini et al. 2011). In a storm event, water level rises and reaches levee surface and starts the erosion process. If there is a flood wall, once the water level reaches the top of the floodwall, overtopping process begins and results in the erosion of the levee. The levee is most likely saturated due to excessive raining prior to overtopping.

Among the methods of characterizing erosion, Erosion Function Apparatus (EFA) developed by Briaud et al. (2001) and Jet Erosion Test (JET) developed by Hanson et al. (2002) are commonly used. Hole erosion test developed by Wan \& Fell (2004) is also a laboratory test used for characterizing erodibility of soils.

During an overtopping event water may impinge the levee surface with different angles depending on the velocity of water overtopping the floodwall. According to the field observations, the angle is often closer to vertical. Karimpour et al. (2014) performed a series of lab-scaled levee-floodwall tests and compared the erosion rate results with EFA results. Levee erosion rates were much higher than the erosion rates measured by EFA tests. Robbins (2012) performed a series of field Jet Erosion Tests on levees constructed with treated clay and compared the results with the results from EFA tests on undisturbed samples as a method to determine the erodibility of the treated levee. The comparison results showed that JET and EFA show different results for lime treated clay and fly-ash treated clay comparing to untreated clay. JET results showed treating the clay does not affect the erodibility while EFA showed it does.

Soil texture and plasticity along with water content and compaction are the dominant parameters in determining soil erodibility (Hanson 2007). Allen et al. (2010) performed a series of submerged jet tests on clay and sand dominated alluvial samples from North Texas embankments and compared the results with total measured scours that happened during the life-time of the embankments to the scour that occurred only during storm events. The results showed higher erosion resistance for clay material during storm. The applicability of jet erosion test (JET) and hole erosion test (HET) in determining the erodibility of cohesive soils were compared by Wahl (2010). It was concluded that JET is better for characterization of different types of soil samples because JET can be used for a broader variety of soil samples while the use of HET is limited due to its inconsistencies and difficulties in measuring weaker and stronger soils. In HET, the weak soil tends to collapse while running the test and hole generation for strong soils is unlikely.

In this paper, a series of JET, EFA, and leveefloodwall tests in two scales of 1:2 and 1:20 were performed to determine the erodibility of materials and correlate levee erosion rate due to floodwall 
overtopping to EFA and JET results as commonly used tests. EFA and JET tests are conducted following the specifications found in Briaud et al. (2001) and ASTM standard D5852, respectively. Low, medium, and high plasticity silty clay material from Mississippi bank with low, medium, and high compaction levels were used in the tests. A combination of JET and EFA was chosen to have both vertical and horizontal components of flow contribute to levee scour prediction. Water in Jet Erosion Test impinges submerged soil surface vertically, and in Erosion Function Apparatus, horizontal flow erodes the soil surface. Water overtopping from floodwalls often impinges the geo-structure - inclined or vertically. Therefore, scour rate and depth prediction can be made using a combination of JET representing the vertical component of flow and EFA representing the horizontal component of flow.

\section{MATERIAL}

Three different sets of material were used for all the tests done in this paper: Non-plastic ML, ML-CL soil with plasticity index of $6 \%$, and ML-CL soil with plasticity index of $9 \%$. Levee-floodwall test was performed on each material with compaction levels of $70 \%, 80 \%$, and $90 \%$ using standard proctor on the dry side of the optimum moisture content. The levee was constructed in five layers using a hand hammer. After compaction of each layer, samples were taken from each layer to verify the compaction level. JET and EFA tests were performed on the same material constructed to match the levee specifications with target compaction levels of $70 \%$, $85 \%$, and $95 \%$. After preparation of the samples, the compaction levels were verified. Levee-floodwall and EFA tests were done on samples with various saturation ratios, however, because JET sample is submerged, only the initial saturation ratio of the sample before soaking was measured.

\section{EXPERIMENTAL PROCEDURE}

\subsection{Levee-Floodwall Simulator}

To simulate levee erosion a scaled levee-floodwall model was constructed in the laboratory to make it possible to run multiple tests in a short time. It is very common in bank of rivers to have floodwalls with exposed height of $2.1 \mathrm{~m}(7 \mathrm{ft})$ as full-sized floodwall. In this study, two scaled models of 1:20 and 1:2 scaled were utilized. For the 1:20 scale, a wooden floodwall was embedded in the soil at the crest of the levee to represent floodwall. The dimensions of the $22.9 \mathrm{~cm}$ wide levee are shown in Figure 1. The water overtopped the floodwall and having a $14 \mathrm{~cm}$ freefall. In addition to the 1:20 scaled levee- floodwall system, to identify the factors that are sacrificed using a small scale, a series of levee tests were performed with a $142 \mathrm{~cm}$ floodwall that was embedded $35 \mathrm{~cm}$ in the levee leaving $107 \mathrm{~cm}$ exposed to represent a larger scale of 1:2 floodwall. In the 1:2 scaled model the water velocity impinging the soil surface is more realistic than the 1:20 scale.

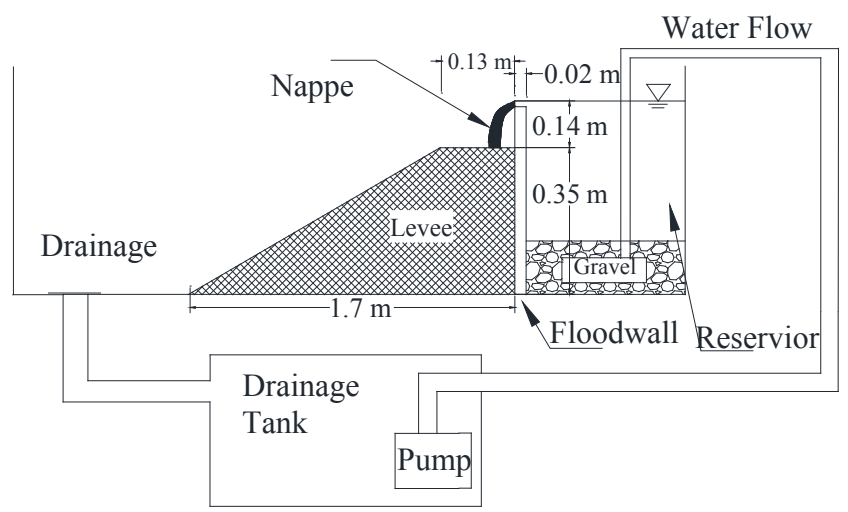

Figure 1. Sketch showing 1:20 scaled levee-floodwall system

After the levee was constructed, a reservoir located in the back of the floodwall was filled with water until it overtopped the floodwall with certain flowrates of 2 and $2.83 \mathrm{~m}^{3} / \mathrm{hr}$ for $1: 2$ scale, and 2.83 and $3.83 \mathrm{~m}^{3} / \mathrm{hr}$ for $1: 20$ scale. Based on the thickness of the generated nappe at the impact point on levee crest and the constant flow, the velocity of the water impinging the soil boundary was calculated. The erosion rate was measured during the test. In majority of the tests, a pool of water was generated as the scour hole was created. Consequently, the scour rate decreased as it was reaching a point where the pool depth was large enough to diffuse the water jet velocity. In this condition the scour rate becomes either zero or constant. This state of erosion process is called equilibrium state in this paper. After equilibrium condition was reached the test was stopped. The average erosion rate from the beginning of the floodwall overtopping to equilibrium condition was then calculated. The average erosion rate is the ratio of scour depth over the elapsed time between beginning of overtopping and the beginning of equilibrium.

\subsection{Jet Erosion Test (JET)}

A laboratory JET apparatus was constructed using specifications provided by ASTM standard D5852. Figure 2 shows the schematics of the apparatus. The water was pumped to a reservoir with $0.91 \mathrm{~m} \mathrm{(3 \textrm {ft } )}$ head. A $44 \mathrm{~cm}$ diameter soil sample was constructed to match the properties of the levee samples. After being submerged, the sample was impinged by water from a $1.3 \mathrm{~cm}$ diameter nozzle located $22 \mathrm{~cm}$ from sample surface. The developed scour depth and pro- 
file was measured through intervals of 600,1200 , 1800,3600 seconds after initiation of test. Critical shear stress, shear stresses, water velocity, and erosion rate were calculated based on equations provided by Hanson (2002) and Hanson (2004).

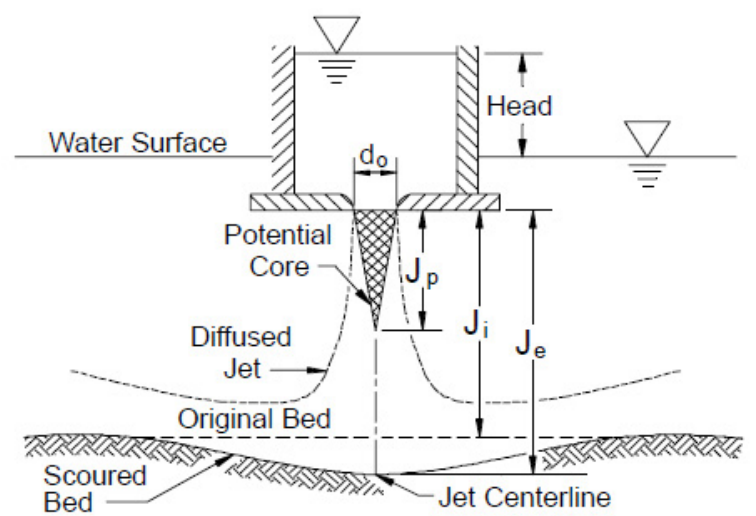

Figure 2. Schematics of vertical laboratory JET apparatus (Hanson 2004)

\subsection{Erosion Function Apparatus}

Generally in EFA tests, an undisturbed soil sample in a 4 inch Shelby tube is pushed for $1 \mathrm{~mm}$ to a water channel with a flow that has certain velocity and the erosion rates are measured for various velocities. For the conducted EFA tests, the samples were constructed in Shelby tubes to control the compaction level, saturation ratio, and plasticity index and to make them comparable with levee and JET tests. Figure 3 shows the specifications of EFA. Erosion rate is calculated when either 1 hour is passed and the sample is eroded less than $50 \mathrm{~mm}$ or the sample is eroded $50 \mathrm{~mm}$ and less than 1 hour is passed. With different water velocities, different erosion rates are achieved. The semi-linear graph of erosion rate versus water velocity is called erosion function. In this study, erosion rate generated from EFA tests on samples is compared to jet erosion and levee erosion rate.

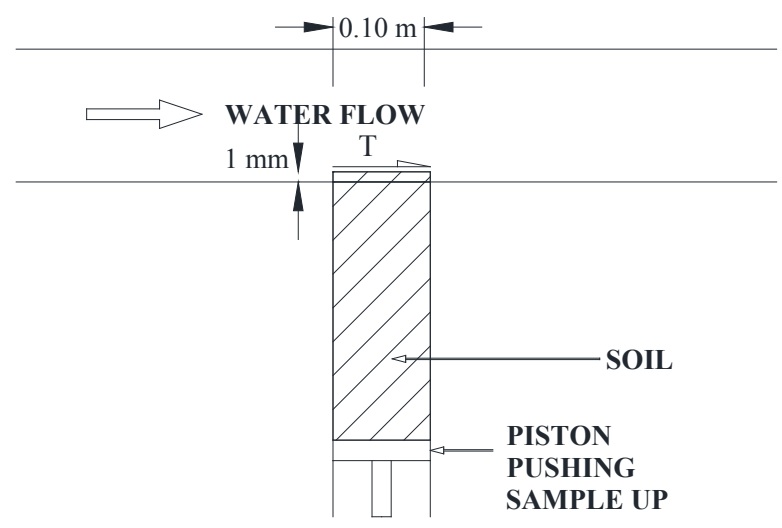

Figure 3. Erosion function apparatus specifications (Briaud et al. 2001)

\section{RESULTS AND DISCUSSION}

\subsection{Jet Erosion Tests}

Ten series of jet erosion tests (JET) were performed on materials with plasticity indices of $0,6 \%$, and $9 \%$ each with three different compaction levels of $70 \%$, $85 \%$, and $95 \%$. The average velocity of the water was then calculated at the sample eroded surface using equations provided by Hanson et al. (2002):

$$
\begin{aligned}
& U_{0}=\sqrt{2 g h} \\
& U / U_{0}=C_{d} d_{0} / J
\end{aligned}
$$

where $U=$ the velocity of water jet at the eroding surface; $U_{0}=$ the velocity of water at JET nozzle; $\mathrm{C}_{\mathrm{d}}$ $=$ the diffusion coefficient assumed to be 6.3 as a typical value; $d_{0}=$ the diameter of the nozzle, i.e., $1.3 \mathrm{~cm}$; and $J=$ the distance of the nozzle from the eroding surface. Erosion rate was then calculated using Equation 3. Erosion rates are plotted in Figure 4.

$$
\dot{z}=k_{d}\left(\tau_{e}-\tau_{c}\right)
$$

where $\dot{z}=$ the erosion rate of JET sample; $k_{d}=$ the erodibility or detachment coefficient; $\tau_{e}=$ the effective hydraulic shear stress; and $\tau_{c}=$ the critical shear stress.

In this paper, critical shear stress was calculated using the method provided by Hanson (2004). Hanson et al. (2002) discusses the detailed calculations in both vertical and inclined JET tests. For calculation of induced shear stress in JET various methods have been proposed by Hanson (2004), Beltaos \& Rajaratnam (1974), Phares et al. (2000), Ghaneeizad et al. (2015), and Carrillo (2015). In this article, the method proposed by Hanson (2004) is used which produces shear stress values with $3 \%$ difference from Beltaos \& Rajaratnam (1974) method and 18\% difference from Carrillo (2015).

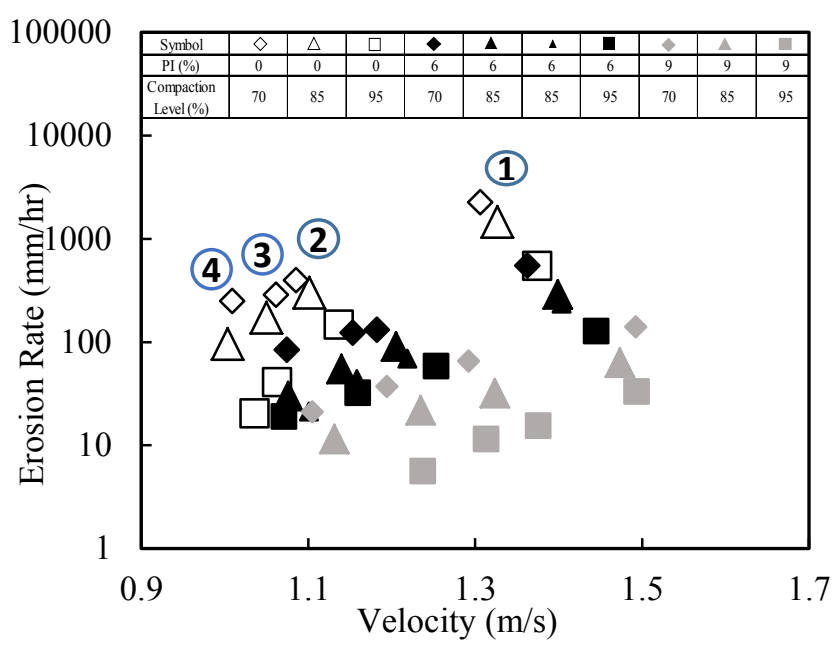

Figure 4. Erosion rate vs. velocity test results for JET tests 
Each JET has 4 points on erosion plots that correspond to the erosion rate measurement at different times. Point 1, 2, 3, and 4 correspond to intervals of $600,1200,1800$, and 3600 seconds after the test initiation, respectively. The results show that the increase of compaction level and the plasticity index result in decrease of the erodibility of the sample. It is shown in Figure 4 that the erosion rates of Point 1 for compaction levels of $90 \%$ to $70 \%$ range from 547 to $2250 \mathrm{~mm} / \mathrm{hr}$, from 127 to $550 \mathrm{~mm} / \mathrm{hr}$, and from 33 to $140 \mathrm{~mm} / \mathrm{hr}$ for plasticity indexes of $0 \%$, $6 \%$, and $9 \%$, respectively. Erosion rates for soils at compaction level of $90 \%$ on average are less than the erosion rates of the ones with $70 \%$ compaction level by a factor of 4.2. However, the erosion rates will increase on average with a factor of 16 when the soils PI changes from 0 to $9 \%$ at same compaction levels (i.e., $70 \%$ or $80 \%$ or $90 \%$ ). Therefore, it can be concluded that the plasticity index is more effective than compaction level reducing the erodibility of the soil. In every JET test, the highest and the lowest erosion rate belong to the Points 1 and 4, respectively. In the sample with 0 PI and $70 \%$ compaction, the erosion rate at the Point 1 was 9 times that of Point 4. In sample with 9 PI and 95\% compaction, the erosion rate for the Point 1 was 6 times that of the Point 4. It is concluded that in this range of erosion rates, Point 1 of JET erosion rates are between 6 and 9 times of Point 4 as a result of jet diffusion.

\subsection{Erosion Function Apparatus Tests}

10 series of EFA tests were performed with respect to JET sample properties. Erosion rate was measured at water velocities of $1 \mathrm{~m} / \mathrm{s}, 2.5 \mathrm{~m} / \mathrm{s}$, and $5 \mathrm{~m} / \mathrm{s}$. Then, the erosion rate versus water velocity was plotted. Figure 5 shows the results of the EFA tests.

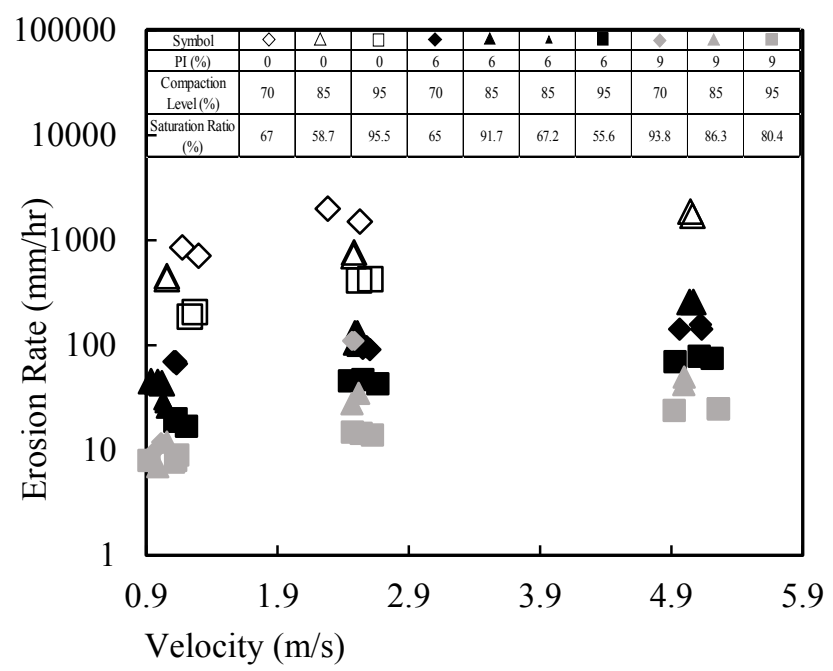

Figure 5. Erosion rate vs. velocity for EFA tests
The results of EFA show that compaction level, plasticity index, and saturation ratio are affecting the erodibility of the samples. It can be shown from Figure 5 that for velocity of $1 \mathrm{~m} / \mathrm{s}$, the erosion rates for samples with $0 \%$ PI range from 207 to 800 $\mathrm{mm} / \mathrm{hr}, 6 \%$ PI range from 17 to $70 \mathrm{~mm} / \mathrm{hr}$, and $9 \%$ PI range from 7 to $12 \mathrm{~mm} / \mathrm{hr}$ for compaction levels of 90 to $70 \%$, respectively. Erosion rate of $90 \%$ is less than erosion rate of $70 \%$ compaction by average factor of 3 . However, erosion rates for PIs of $0 \%$ to $9 \%$ range from 12 to $850 \mathrm{~mm} / \mathrm{hr}, 8$ to $450 \mathrm{~mm} / \mathrm{hr}$, and 7 to $190 \mathrm{~mm} / \mathrm{hr}$ for 70,80 , and $90 \%$ compaction levels, respectively. Erosion rate of PI of $9 \%$ for the same compaction level is less than PI of $0 \%$ by average factor of 51. Therefore, it can be concluded that plasticity index is more effective than compaction level in mitigating the erodibility of the soil. The effect of saturation ratio in EFA results is more significant than JET results as mentioned earlier. As the compaction level and plasticity increase, the erosion rate decreases while as the saturation ratio increases the erosion rate decreases. The rate of increase in erosion rate relative to water velocity is almost constant for various material type and linear in a semi-log scale plot as shown in Figure 5. For all tests, the erosion rate of $5 \mathrm{~m} / \mathrm{s}$ water velocity is between 3 to 4 times that of $1 \mathrm{~m} / \mathrm{s}$ velocity.

\subsection{Simulated Levee-Floodwall}

Total of 45 simulated levee-floodwall tests were performed with 1:20 and 1:2 scaled floodwalls. The erosion rates were measured from the initiation of overtopping until the equilibrium was reached. In weaker samples with low plasticity and low compaction level, the equilibrium condition was not achieved with constant flow as all the levee was washed away. The average of the measured erosion rates was then calculated for each test via dividing scour depth when equilibrium is reached by time. Average erosion rate is useful to predict the scour depth when overtopping occurs to determine the failure of the floodwall. Figure 6 shows the average erosion rates for the 45 tests. The vertical axis shows the test numbers of the levee-floodwall tests. For each test, plasticity index, compaction level (CL), saturation ratio (SR), and flow rate are specified. Plasticity having the highest effect on erosion rate, is followed by compaction and saturation ratio. Also, the erosion rates of the 1:2 scale are 3.4 times higher than 1:20 scale with similar soil properties on average. 


\begin{tabular}{|c|c|c|c|c|c|}
\hline $\begin{array}{c}\text { Test } \\
\text { No. }\end{array}$ & PI (\%) & CL & SR & Flow & \\
$(\%)$ & $(\mathrm{m} 3 / \mathrm{hr})$ & Scale \\
\hline 1 & 0 & 70 & 44 & 3 & $1: 20$ \\
\hline 2 & 0 & 70 & 48 & 3 & $1: 20$ \\
\hline 3 & 0 & 70 & 70 & 3 & $1: 20$ \\
\hline 4 & 0 & 70 & 35 & 3 & $1: 20$ \\
\hline 5 & 0 & 70 & 24 & 3 & $1: 20$ \\
\hline 6 & 0 & 70 & 54 & 3 & $1: 20$ \\
\hline 7 & 0 & 80 & 44 & 3 & $1: 20$ \\
\hline 8 & 0 & 80 & 75 & 3 & $1: 20$ \\
\hline 9 & 0 & 80 & 20 & 3 & $1: 20$ \\
\hline 10 & 0 & 80 & 23 & 3 & $1: 20$ \\
\hline 11 & 0 & 80 & 26 & 3 & $1: 20$ \\
\hline 12 & 0 & 80 & 61 & 3 & $1: 20$ \\
\hline 13 & 0 & 90 & 44 & 3 & $1: 20$ \\
\hline 14 & 0 & 90 & 80 & 3 & $1: 20$ \\
\hline 15 & 0 & 90 & 41 & 2 & $1: 2$ \\
\hline 16 & 0 & 90 & 48 & 3 & $1: 2$ \\
\hline 17 & 0 & 90 & 70 & 3 & $1: 20$ \\
\hline 18 & 0 & 90 & 48 & 3 & $1: 20$ \\
\hline 19 & 0 & 90 & 46 & 3 & $1: 2$ \\
\hline 20 & 0 & 90 & 46 & 3 & $1: 20$ \\
\hline 21 & 6 & 70 & 68 & 3 & $1: 20$ \\
\hline 22 & 6 & 70 & 19 & 3 & $1: 20$ \\
\hline 23 & 6 & 70 & 30 & 3 & $1: 2$ \\
\hline 24 & 6 & 70 & 41 & 3 & $1: 20$ \\
\hline 25 & 6 & 80 & 91 & 5 & $1: 20$ \\
\hline 26 & 6 & 80 & 30 & 3 & $1: 20$ \\
\hline 27 & 6 & 80 & 30 & 3 & $1: 20$ \\
\hline 28 & 6 & 80 & 38 & 4 & $1: 20$ \\
\hline 29 & 6 & 80 & 72 & 4 & $1: 20$ \\
\hline 30 & 6 & 80 & 42 & 3 & $1: 2$ \\
\hline 31 & 6 & 80 & 44 & 3 & $1: 20$ \\
\hline 32 & 6 & 90 & 47 & 3 & $1: 20$ \\
\hline 33 & 6 & 90 & 43 & 2 & $1: 2$ \\
\hline 34 & 6 & 90 & 39 & 3 & $1: 2$ \\
\hline 35 & 6 & 90 & 28 & 3 & $1: 2$ \\
\hline 36 & 6 & 90 & 53 & 3 & $1: 20$ \\
\hline 37 & 9 & 70 & 49 & 3 & $1: 20$ \\
\hline 38 & 9 & 70 & 40 & 3 & $1: 2$ \\
\hline 39 & 9 & 70 & 51 & 3 & $1: 20$ \\
\hline 40 & 9 & 80 & 47 & 3 & $1: 2$ \\
\hline 41 & 9 & 80 & 61 & 3 & $1: 20$ \\
\hline 42 & 9 & 90 & 48 & 2 & $1: 2$ \\
\hline 43 & 9 & 90 & 48 & 3 & $1: 2$ \\
\hline 44 & 9 & 90 & 53 & 3 & $1: 2$ \\
\hline 45 & 9 & 90 & 55 & 3 & $1: 20$ \\
\hline
\end{tabular}

Average Erosion Rate $(\mathrm{mm} / \mathrm{hr})$
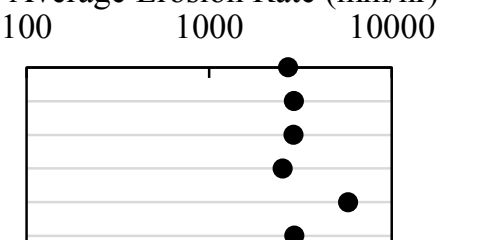

$\dot{z}=S D Q F \sqrt{C_{1} J^{2}+C_{2} E^{2}}$

Table 1. Prediction model variable explanation

\begin{tabular}{lll}
\hline Variable & Description & Value \\
\hline$\dot{\mathbf{z}}$ & $\begin{array}{l}\text { Average erosion } \\
\text { rate in overtopped lev- } \\
\text { ees }\end{array}$
\end{tabular}
factor $\sqrt{\frac{\text { Levee saturation ratio }}{\text { EFA sample saturation ratio }}}$ D JET diffusion fac- $\begin{array}{r}1,2.3,7.5 \text { for plasticity in- } \\ \text { dices of } 0,6 \text {, and } 9 \text { respectively }\end{array}$

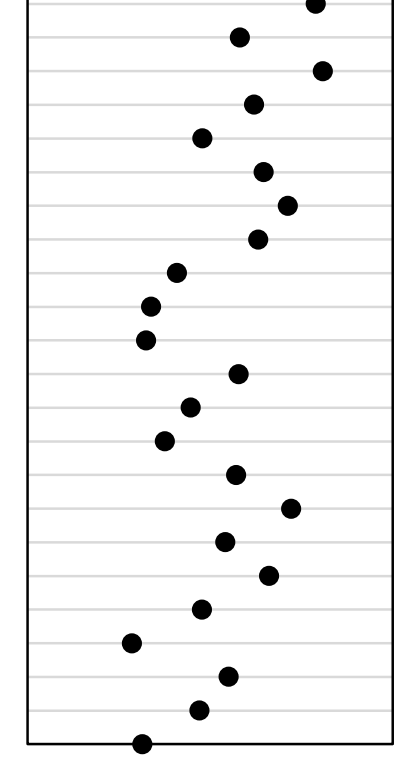

$\left(\frac{\text { Flow rate }\left(\frac{m^{3}}{h r}\right)}{2.83}\right)^{3}$

$\mathrm{F}$

Scaling factor

$2.5887 \times$ floodwall $H+0.64$

$\mathrm{C}_{1}$

JET weight factor

2.6

$\mathrm{C}_{2}$

EFA weight factor

1

$\mathrm{J}$

JET erosion rate at $600 \mathrm{~s}$ interval $(\mathrm{mm} / \mathrm{hr})$

Measured from test

$\mathrm{E}$

EFA erosion rate at $1 \mathrm{~m} / \mathrm{s}(\mathrm{mm} / \mathrm{hr})$
For example, Test No. 44 has plasticity index, compaction level, and saturation ratio of $9 \%, 90 \%$, and $53 \%$, respectively. The sample was placed in 1:2 scaled levee-floodwall simulator, run by water with flow rate of $2.83 \mathrm{~m}^{3} / \mathrm{hr}$. JET and EFA tests were performed on a samples with similar specifications to the levee test sample. Levee erosion rate, EFA erosion rate at $1 \mathrm{~m} / \mathrm{s}$ and JET erosion rate at 600 second interval were measured at 890,9 , and $33.06 \mathrm{~mm} / \mathrm{hr}$, respectively. EFA sample had $80.44 \%$ saturation ratio. Table 2 shows a summary of variables for levee Test No. 44. pingement is vertical. It was shown that in JET, erosion rate drops drastically for 1200,1800 , and 3600 seconds intervals due to high diffusion of water jet; therefore, in this article, the erosion rate of JET corresponding to 600 seconds interval is used to develop a correlation between JET, EFA, and levee erosion rates. Using the collected data and the trends found in the tests, the following prediction model 
Table 2. Variables table for levee test 44

\begin{tabular}{lll}
\hline Variable & \multicolumn{1}{c}{ Description } & Value \\
\hline $\mathrm{S}$ & Saturation ratio factor & 0.812 \\
$\mathrm{D}$ & JET diffusion factor & 7.5 \\
$\mathrm{Q}$ & Flow rate factor & 1 \\
$\mathrm{~F}$ & Scaling factor & 3.4 \\
$\mathrm{C}_{1}$ & JET weight factor & 2.6 \\
$\mathrm{C}_{2}$ & EFA weight factor & 1 \\
$\mathrm{~J}$ & JET erosion rate at & $33.06 \mathrm{~mm} / \mathrm{hr}$ \\
$\mathrm{E}$ & 600s interval & \\
& EFA erosion rate at & $9 \mathrm{~mm} / \mathrm{hr}$ \\
\hline
\end{tabular}

Hence, the estimated erosion rate for Test No. 44 from the beginning of overtopping until equilibrium, is estimated $1119 \mathrm{~mm} / \mathrm{hr}$ using the model.

\subsection{Model Verification}

Out of the 45 performed levee-floodwall tests, 17 were used to derive the prediction model. After the equation was developed, the other remaining 28 tests that measured erosion rates were used to verify the developed prediction model. The 28 performed tests consisted of $0 \%, 6 \%$, and $9 \%$ plasticity index with $70 \%, 80 \%$, and $90 \%$ compaction level with various flowrates. Figure 7 shows predicted levee erosion rate using the model versus actual measured erosion rates for the 28 performed simulated levee-floodwall tests.

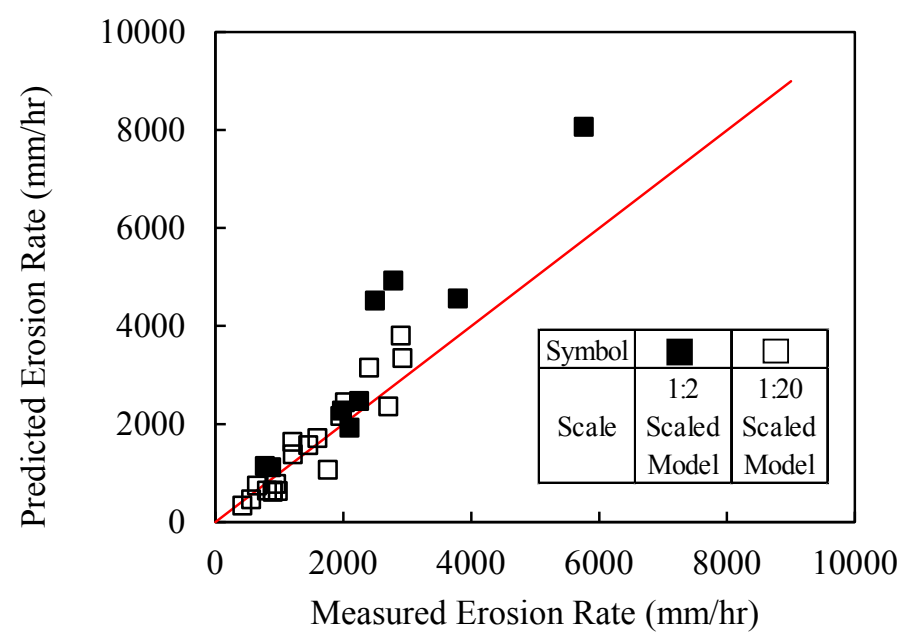

Figure 7. Levee prediction model evaluation

Out of 28 levee-floodwall tests used for verification, erosion rates for 23 of them were predicted with minimal error. Most of these tests had erosion rates of lower than $3000 \mathrm{~mm} / \mathrm{hr}$. Only in 4 tests with erosion rates higher than $3000 \mathrm{~mm} / \mathrm{hr}$, the prediction erosion rates were noticeably higher than measured values. The mentioned 4 tests with Test Nos. of 3, 5,
11, and 23 (see Figure 6 for details) had the lowest compaction level or the lowest plasticity index or were 1:2 scaled models. It was also found that those tests had not reached equilibrium condition where the scour rate becomes zero or constant due to low plasticity or low compaction level or usage of taller floodwall. Erosion would continue if the scaled model was large enough for the pool of water to become deep enough to diffuse water velocity and consequently the induced shear stress until equilibrium was reached. It was concluded that the actual erosion rate would be higher and closer to the agreement line in Figure 7. Therefore, it can be concluded the proposed correlation can provide a reasonable estimation of erosion rates for overtopped floodwalls.

\subsection{Simplified Prediction Model}

The EFA coefficient $\left(\mathrm{C}_{2}\right)$ is the weight factor for EFA erosion rate at $1 \mathrm{~m} / \mathrm{s}$ water velocity in the proposed model. It was shown in the performed tests that erosion rates in EFA tests are significantly lower than levee and JET tests. Also, in the process of calibration of prediction model, the derived $\mathrm{C}_{2}$ coefficient was less than $\mathrm{C}_{1}$ which is the weight factor for JET erosion rate at 600 second interval. In this section, the proposed prediction model is evaluated as if $\mathrm{C}_{2}$ is zero and EFA is eliminated to identify a simpler version of the model. If EFA is eliminated from the equation, the saturation factor ' $S$ ' becomes irrelevant so it is assumed to be equal to 1 ; therefore, the prediction model will be converted to the following simplified model, i.e., Equation 5.

$$
\dot{z}=D Q F \sqrt{C_{1} J^{2}}
$$

The erosion rates of the performed levee tests were repredicted with the simplified prediction model. Figure 8 shows the new estimation of levee erosion rates using merely JET results. In this figure, the results from the levee tests used to develop the correlation are included as well (total of 45 tests).

The erosion rates of the performed levee tests were repredicted with the simplified prediction model. Figure 8 shows the new estimation of levee erosion rates using merely JET results. In this figure, the results from the levee tests used to develop the correlation are included as well (total of 45 tests). 


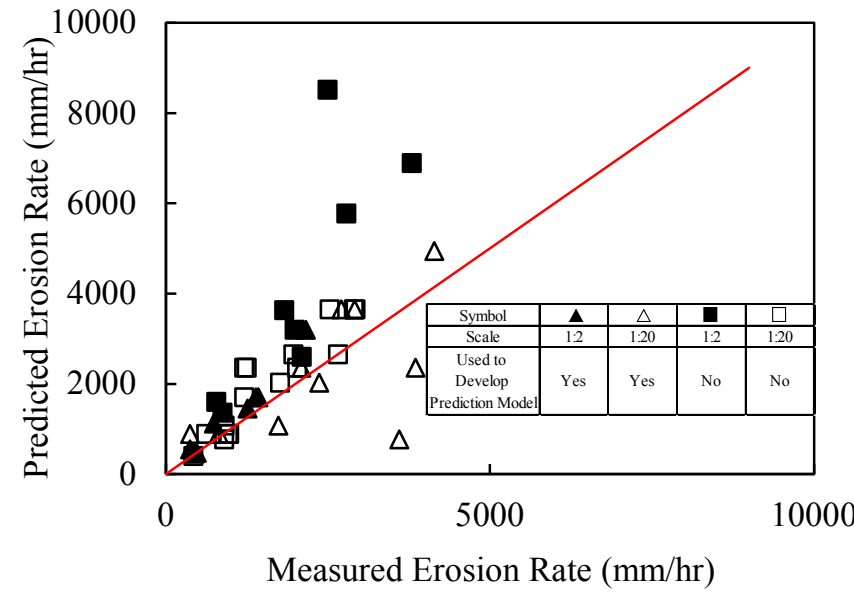

Figure 8. Simplified model evaluation, the results consist of the tests used in developing the original prediction model

It is shown that by neglecting the EFA results, the simplified model is still providing reasonable estimate of erosion rate but with higher average error rate of $35 \%$ and on the conservative side. The simplified model has the following advantages for estimations of levee erosion rate: 1) The test can be performed in-situ using field Jet Erosion Test apparatus; 2) it eliminates the need of running an expensive laboratory test and dealing with sampling and sample disturbance errors; 3) It provides a rough estimate of erosion rate within only 10 minutes of running JET test.

\section{CONCLUSION}

Performing full-scaled levee-floodwall simulated tests to predict scour depth and floodwall failure in a storm event can be expensive, difficult, and time consuming. Many erosion measuring apparatuses have been developed throughout the years. In this study, Jet Erosion Test and Erosion Function Apparatus were chosen as alternative tests for simulated levee tests. 10 JETs and EFA tests were performed on samples with various compaction, plasticity, and saturation ratios. 17 levee tests were conducted with scales of 1:20 and 1:2 scaled floodwall. The erosion rate was measured for each test from the moment floodwall overtopping started until the equilibrium condition was reached where the scouring rate is zero or constant. It was observed that although EFA and JET do not provide close values to levee erosion rates, the trend they follow for compaction, plasticity index and saturation ratio is identical.

Using the mentioned trend, a prediction model was proposed to predict levee erosion rates via JET and EFA tests. The model was then evaluated by performing 28 more levee tests and comparing the predicted erosion rates using the actual measured erosion rates in the levee tests. In weaker soils, the equation predicted higher values for levee erosion rates than measured values. It was concluded that because the scaled model of levee in this study was not large enough, the equilibrium condition would never be reached for weaker samples and the scouring continues until the levee is totally washed away. If the scaled model was larger, it is assumed that the measured values would be closer to the predictions. Then, a simplified version of the model was introduced and evaluated. The simplified equation produced less accurate but still acceptable erosion rate predictions. The simplified equation does not require an expensive laboratory test such as EFA, it eliminates sample disturbance errors, and allows predicting reasonable erosion rates using JET in-situ test in shorter amount of time.

\section{REFERENCES}

Allen, P., Capello, S., \& Coffman, D. (2010). Comparison of submerged jet testing to field erosion rates in clay and sand channels, blackland prairie ecosystem, Texas. 2nd Joint federal interagency conference. Las Vegas.

ASTM-D5852. (2007). Standard test method for erodibility determination of soil in the field or in the laboratory by the jet index method. Philadelphia: Annual book of ASTM standards.

Briaud, J., Chen, H. C. , Govindasamy, A., \& Storesund, R. (2008). Levee erosion bu overtoppin gin New Orleans during the Katrina hurricane. Journal of geotechnical and geoenvironmental engineering, 618-631.

Briaud, J., Ting, F., Chen, H., Cao, Y., Han, W., \& Kwak, K. (2001). Erosion function apparatus for scour rate predictions. Journal of geotechnical and geoenvironmental engineering, 105-113.

Carrillo, V. (n.d.). Numerical investigation of the shear stress distribution resulting from a turbulent impinging jet. Pullman, WA: MS Thesis, Washington State University.

Ghaneezad, S. M., Atkinson, J. F., \& Bannett, S. J. (2015). Effect of flow confinement on the hydrodynamics of circular impinging jets: implications for erosion assessment. Environmental Fluid Mechanics, 15(1), 1-25.

Gross, J., Stuetzle, C., Chen, Z., Cutler, B., Franklin, W., \& Zimmie, T. (2010). Simulating levee erosion with physical modeling validation. International conference of scour and erosion, (pp. 326-337).

Hanson, G. J., \& Cook, K. R. (2004). Apparatus, test procedures, and analytical methods to measure soil erodibility in situ. Applied engineering in agriculture, 455462.

Hanson, G., \& Hunt, S. (2007). Lessons learned using laboratory JET method to measure soil erodibility of compacted soils. Applied engineering in agriculture, 305312.

Hanson, G., Robinson, K., \& Cook, K. (2002). Scour bellow an everfall: Part II. Prediction. Transactions of the ASAE, 957964.

Karimpour, M., Heinzl, K., Stendback, E., Galle, K., Zamiran, S., \& Osouli, A. (2015). Scour characteristics of saturated levees due to floodwall overtopping. IFCEE, (pp. 12981307).

Mercier, F., Bonelli, F., Anselmet, F., Pinettes, P., Courivaud, J., \& Fry, J. (2012). On the numerical modelling of the Jet Erosion Test. ICSE6 (pp. 601-608). Paris: ICSE6.

Phares, D. J., Smedley, G. T., \& Flagan, R. C. (2000). The wall shear stress produced by the normal impingement of a jet 
on a flat surface. Journal of Fluid Mechanics, 418, 351375.

Rajaratnam, N., \& Beltaos, S. (1977). Erosion by Impinging Cicular Turbulent Jets. Journal of the Hydraulics DivisionsASCE, 103(10), 1191-1205.

Robbins, B., \& Wibowo, J. (2012). Field jet erosion tests of treated clay levee embankments. ICSE6 (pp. 1239-1246). Paris: ICSE6.

Villarini, G., Smith, J., Baeck, M., \& Krajewski, W. (2011). Examining flood frequency distributions in the Midwest U.S. American water resources association, (p. 447).

Wahl, T. L. (2010). A comparison of the hole erosion test and Jet Erosion Test. Joint federal interagency conference on sedimentation and hydrologic modeling. Las Vegas. 